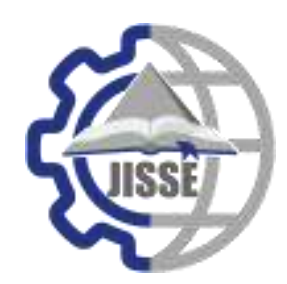

\begin{tabular}{c}
\hline \hline JISSE \\
ISSN: 2636-4425 \\
\hline \hline
\end{tabular}

\title{
Stress Analysis of a Shredder Blade for Cutting Waste Plastics
}

\author{
M. F. Nasr ${ }^{*}, 1$ and K. A. Yehia ${ }^{1}$ \\ ${ }^{*}$ National Research Centre, Mechanical Engineering Department, Dokki, Giza, Egypt
}

\begin{tabular}{l} 
A R T I C L E I N F O \\
\hline Article history: \\
Received:30-11-2019 \\
Accepted:09-12-2019 \\
Online:12-12-2019
\end{tabular}

Keywords:

Waste Plastics

Shredder Blades

Material

Stress Analysis

\begin{abstract}
A B S T R A C T
This paper presents a procedure for static stress analysis of a given shredder blade with three cutting edges used for cutting Polyethylene Terephthalate (PET) waste plastics. Solid Works was used for generating the blade geometry and shape. This procedure gives detailed steps for calculating the distributed applied cutting forces at the edge of the blade. The blade material is selected to be low carbon steel with known physical and mechanical properties. Finite Element Analysis with ANSYS is then implemented for calculating the induced stresses and strains throughout the blade structure. The 3D modeling of the blade was imported to the ANSYS. Finite element -type "SOLID 185" was implemented for the present stress analysis. Meshing of the 3D model has been implemented with smart mesh density (level 3) It was found from attained results that the maximum stress resulting from the applied cutting forces is well below the allowable stress of the blade material.
\end{abstract}

\section{Introduction}

Plastics are one of the most essential engineering materials that used in various applications. They are used in the form of sheets, bottles, packages, pipes and other purposes, such as for holding and packaging foods and drinks [1]. Used plastics (wastes) can be converted into raw materials by utilizing an appropriate mechanical technology such as shredding, as shown in Figure 1, or extrusion. The second step is melting and finally converting to new products. The shredder blade plays the major role in the plastic shredder machine. There are many types and shapes of shredder blades [2] depicted in Figure 2. A Shredder can have single shaft, two shafts or four shafts according to the types of materials to be shred.

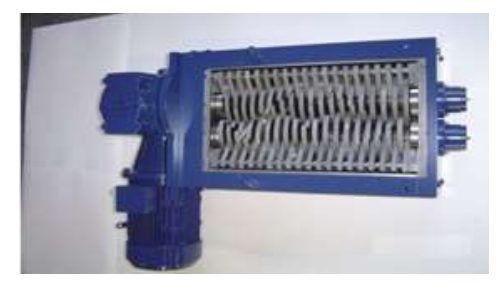

Figure 1: Plastic shredder machine

\footnotetext{
${ }^{*}$ M. F. Nasr, National Research Centre, Mechanical Engineering Department, Dokki, Giza, Egypt, +201223216615\& mf_nasr@yahoo.com
}

Generally, solid wastes can be classified according to their source such as: municipal solid waste, industrial solid waste and agricultural solid waste [3]. Plastic waste is a constituent of the solid waste set of which Polyethylene Terephthalate (PET) is a common material of manufacture. PET is used to produce plastic bottles and several other plastic products.

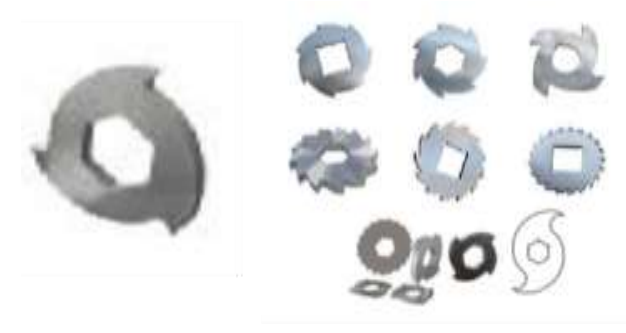

Figure 2: Types of shredder blades

A. Tegegne, et al [1] developed an electrically driven dual shafted-multi bladed shredder machine for recycling waste plastics. Angle and sharpness of the blades, space between the blades etc. were considered. Tool steel ASIS L-2 was the steel type selected for blades with angle of cutting equals to $56^{\circ}$. R. Ekman [4] designed and manufactured a shredder machine for plastic waste material recycling. 
He used a motor of $2.2 \mathrm{KW}$ and $2820 \mathrm{rpm}$ for giving the required power to shred plastic bottles. He used a gearbox of reduction ratio 40 to reach $70 \mathrm{rpm}$ for shredding speed. M. Sakthivel, et al [5] designed a twin shaft shredder using ProEngineer software, the number of blades of the shredder was 16 on each shaft, and the output power required was $2 \mathrm{Hp}$. Alloy steel with composition of $20 \mathrm{MnCr} 5$ has been used for manufacturing the shredder blades. S. B. Pavankumar, et al [6] designed and fabricated organic waste shredding machines, where the cutting blades are made of high carbon steel. A planetary gearbox with output speed $96 \mathrm{rpm}$ was utilized.

\section{A Procedure for Estimating the Applied Cutting Force}

In this research a shredder blade with three cutting edges is used for plastic shredding machine. The geometry and shape of a single blade has been generated using Solid Works 16. The blade has hexagonal hole for fixing the drive shaft. All dimensions are illustrated in Figure 3.

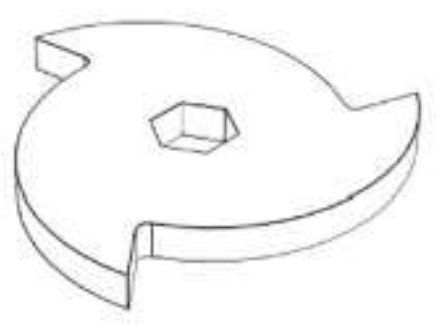

3a: Isometric

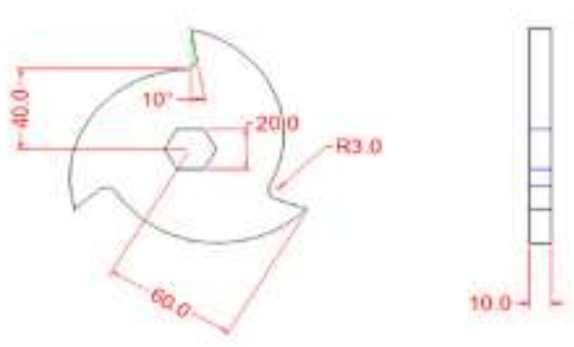

3b: Planes Views

Figure 3: Detailed geometry of the shredder blade (Dimensions are in $\mathbf{m m s}$ )

The procedure for determining the distributed applied cutting (shredding) force at the edge of the blade is illustrated in the flow chart given in Figure 4.

In this study the plastic material to be cut is selected to be PET material (Polyethylene Terephthalate) with mechanical properties given in Table 1.

Table 1: Mechanical properties of PET material [7]

\begin{tabular}{|l|c|}
\hline Coefficient of friction $(\boldsymbol{\mu})$ & From $\mathbf{0 . 2}$ to 0.4 \\
\hline Hardness (RC) & From $\mathbf{9 4}$ to 101 \\
\hline Poisson's ratio (v) & From $\mathbf{0 . 3 7}$ to $\mathbf{0 . 4 4}$ \\
\hline Tensile modulus $(\mathbf{G P a})$ & From $\mathbf{2}$ to $\mathbf{4}$ \\
\hline Tensile strength $(\mathbf{M P a})$ & $\mathbf{8 0}$ \\
\hline Yield strength $(\mathbf{M P a})$ & $\mathbf{6 4}$ \\
\hline
\end{tabular}

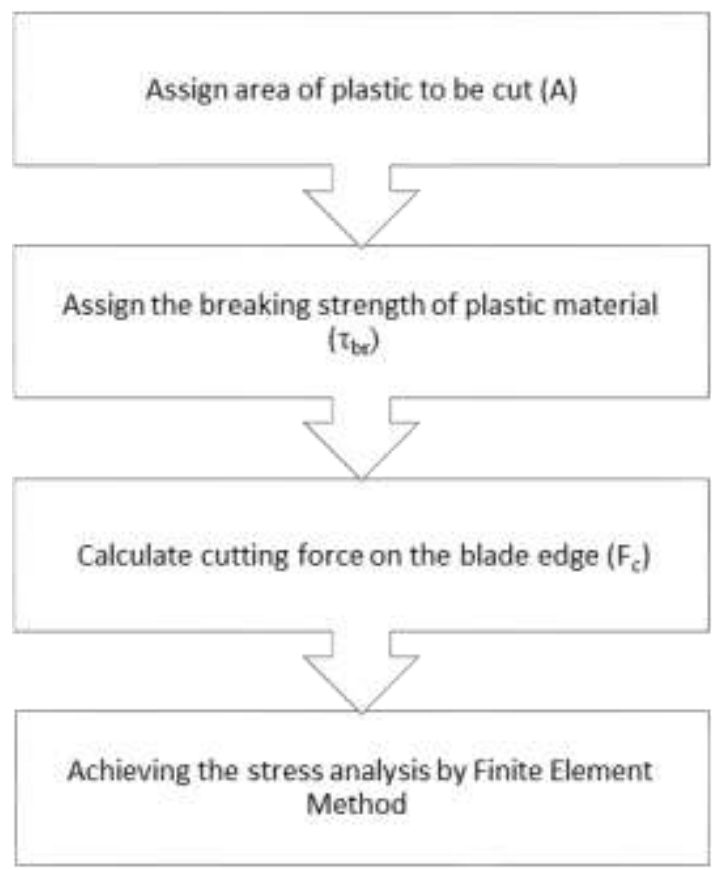

Figure 4: Flow chart for calculating the shredding force.

Breaking strength can be assumed as the ultimate strength multiplied by a factor of safety 1.5

Breaking strength of PET plastic material:

$$
\tau_{\text {br) plastic }}=1.5 * 80=120 \mathrm{MPa}
$$

The cross-sectional area of the material to be cut is

$$
A=w^{*} t
$$

Where: $\mathrm{w}=$ Width of cutting blade edge,

$$
\mathrm{t}=\text { Thickness of the plastic material }
$$

The cutting force required for cutting the plastic bottles

$$
F_{c}=\tau_{\text {br)plastic }} * A
$$

\section{A Case Study and Results}

A case study including the determination of the force required for cutting PET plastic bottles and proceeding stress analysis with ANSYS for the shredder blade is presented.

\subsection{Geometry of the blade}

The blade is assigned with (refer to Figure 3):

$\mathrm{w}=0.01 \mathrm{~m}, \mathrm{Ro}=0.06 \mathrm{~m}, \mathrm{R}_{\text {hole }}($ hexagonal circle $)=0.01 \mathrm{~m}$

The thickness of plastic bottles is assumed to be $\mathrm{t}=5^{*} 10^{-4} \mathrm{~m}$, the cutting area of plastic is

$$
A=w^{*} t=0.01 * 5 * 10^{-4}=5 * 10^{-6} m^{2}
$$




\subsection{Material and Manufacturing Method}

In this paper the blades are made of low carbon steel with ultimate tensile strength of $440 \mathrm{MPa}$, Yield strength of $370 \mathrm{MPa}$, Elastic modulus of $205 \mathrm{GPa}$, and Poisson's ratio of 0.29 . The shredder blades can be manufactured by milling machines using end mill and slot drill tools to produce the required hexagonal holes, outer surfaces and cutting angles.

\subsection{Cutting force}

The cutting force $F_{c}=\tau_{\text {br) plastic }} * A=120 * 5=600 \mathrm{~N}$

\subsection{Stress Analysis of the Shredder Blade Using FEM}

FEM was applied for stress analysis of the shredder blade using ANSYS 19.2 software. 3D modeling of the blade was imported to the ANSYS. The analysis considered only static stresses and strains; no vibration or dynamic analysis was considered. The element type is SOLID 185

Meshing of the 3D model has been implemented with smart mesh density (level 3). Figure 5 illustrates the model after refine meshing.

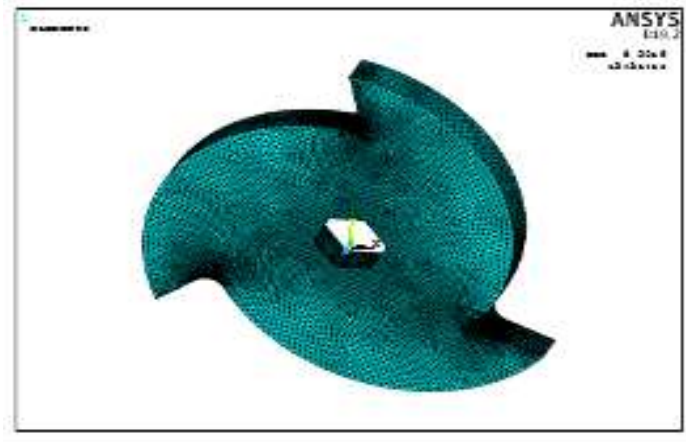

Figure 5: Shredder Blade Meshing

The boundary conditions were determined in the model; the hexagonal hole in blade center has been fixed in all coordinate directions. The calculated cutting force $(600 \mathrm{~N})$ was applied on the blade top edge and distributed along the nodes on this line as shown in Figure 6 below.

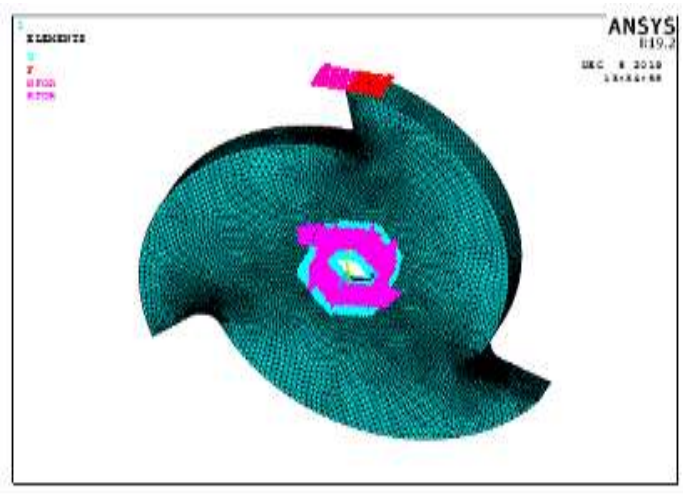

Figure 6: Shredder Blade with applied loads and boundary conditions

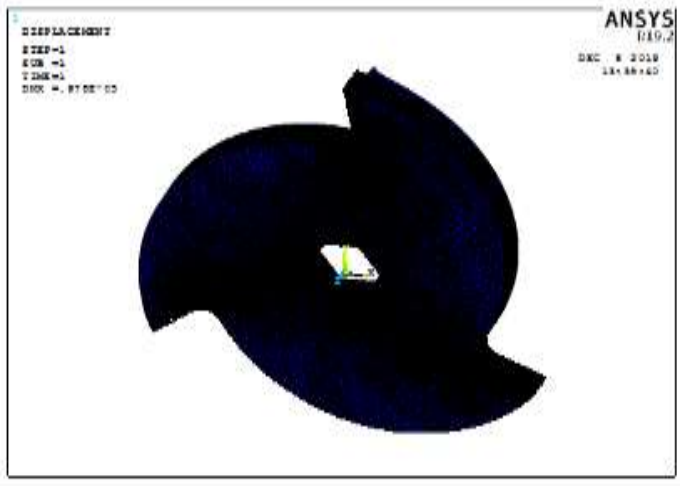

Figure 7: Shredder Blade Deformed Shape

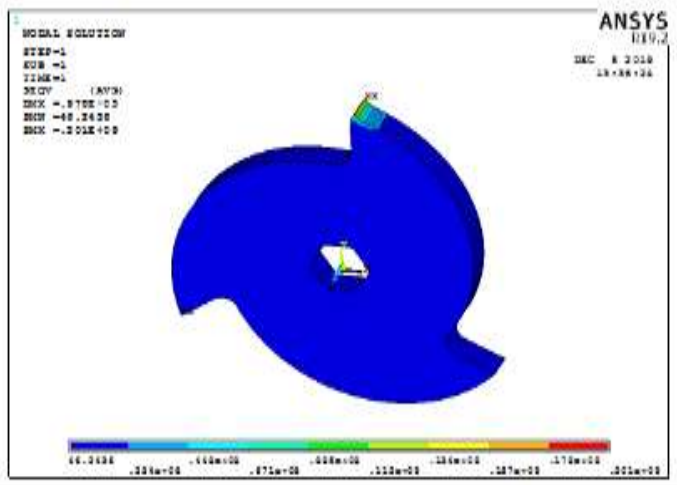

Figure 8: Von Misses Stress

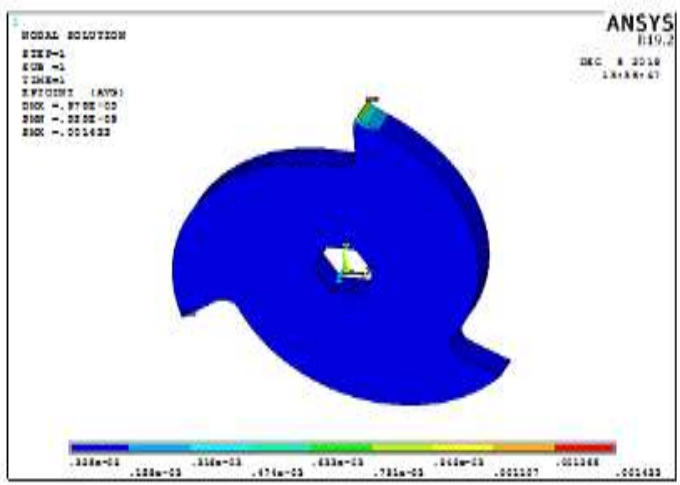

Figure 9: Total Mechanical Strain

The results obtained from the ANSYS (as illustrated in Figures 7,8 and 9) indicates that the maximum Von Misses stress is $201 \mathrm{MPa}$, which is safe in values compared to the yield stress of the blade material.

The maximum total mechanical strain is $1.4^{*} 10^{-3}$, and the maximum deformation is $0.97 * 10^{-5} \mathrm{~m}$.

For other researches that analyzed the shredder blades with ANSYS, Sekar Ravi [8] analyzed the plastic shredder blade with two cutting edges by ANSYS using heat treated mild steel, and outer diameter of $100 \mathrm{~mm}$ and thickness of $5 \mathrm{~mm}$. He found that the maximum stress is $2.5 \mathrm{MPa}$, the maximum strain is $1.2 * 10^{-5}$, and maximum deformation $4 * 10^{-6} \mathrm{~mm}$. 
Cristian Pedraza et al. [9] used AISI 1045 with elastic limit of $530 \mathrm{MPa}$ and D6AC with elastic limit of $1310 \mathrm{MPa}$ as materials for designing and analysis the shredder blades with ANSYS. The affecting shredding forces was $8825 \mathrm{~N}$. It was found that the maximum stress for AISI 1045 was $374 \mathrm{MPa}$ and minimum stress of $65 \mathrm{~N} / \mathrm{m}^{2}$. For D6AC, the maximum stress is $374 \mathrm{MPa}$ and minimum stress is $772 \mathrm{~N} / \mathrm{m}^{2}$.

\section{Conclusions}

The shredding machine for cutting waste plastics is widely used in industries for the plastic waste management. In this research paper a shredder blade is developed using Solid Works, and the stress analysis has been performed using ANSYS. The material of the blades and method of manufacturing were being demonstrated.

The results obtained by the Finite Element Analysis illustrated that the stresses to which they will be subjected in the process of shredding PET plastic material are well below the yield stress of blade material. Vibration and dynamic stress analysis of shredder blades are under investigation for a future study.

\section{Conflict of Interest}

The authors declare no conflict of interest.

\section{References}

[1] A.Tegegne, A. Tsegaye, E. Ambaye, R. Mebrhatu "Development of Dual Shaft Multi Blade Waste Plastic Shredder for Recycling Purpose", International Journal of Research and Scientific Innovation (IJRSI) | Volume VI, Issue I, 2019

[2] S. VijayAnanth, T.N. Sureshkumar, C. Dhanasekaran , A. Aravinth KumarA, "Design and Fabrication of Plastic Shredder Machine for Clean Environment ", International Journal of Management, Technology And Engineering, Volume 8, Issue XII, 2018

[3] D. Atadious, and O. Joel, " Design and Construction of a Plastic Shredder Machine for Recycling and Management of Plastic Wastes ", International Journal of Scientific and Engineering Research, 2018

[4] R. Ekman, "Development of a Plastic Shredder ", master thesis, Sweden, Lund University, 2018

[5] M. Sakthivel, G. Rajeshkannan, M. Naveenkumar, M. Muralimanokar, " Design And Analysis of Twin Shaft Shredder Using Pro-E And Hyperworks Software" International Journal of Advanced Research in Basic Engineering Sciences and Technology (IJARBEST), Vol.3, Special Issue.24, 2017

[6] S.B. Pavankumar, K.R. Sachin , R. Shankar, B. Thyagaraja, T. Madhusudhan, " Design and Fabrication of Organic Waste Shredding Machine " International Journal of Engineering Science Invention (IJESI) ISSN (Online): 2319 - 6734, |Volume 7 Issue 6 Ver III, 2018

[7] F. J. Shackelford and W. Alexander, " Materials Science And Engineering Handbook," CRC Press LLC, 2001

[8] S. Ravi, “ Utilization of Upgraded Shredder Blade and Recycling the Waste Plastic and Rubber Tyre", in 2018 Proceedings of the International Conference on Industrial Engineering and Operations Management Paris, France, 2018.

[9] C.P, Yepes, P.R. Miguel Angel and P.M. José, "Analysis by Means of the Finite Element Method of the Blades of a PET Shredder Machine with Variation of Material and Geometry", Contemporary Engineering Sciences, Vol. 11, no. 83, 2018 